\title{
Qual visualidade para o êxodo em massa? ${ }^{1}$ Which visibility for the mass exodus?
}

\author{
Vincent Lavoie \\ Vincent Lavoie est directeur du centre de recherche sur le texte et l'imaginaire Figura (UQAM). Professeur titulaire au \\ département d'histoire de l'art de l'Université du Québec à Montréal, il a notamment publié La preuve par l'image (Québec, \\ Presses de l'université du Québec, 2017) et L'Affaire Capa. Le procès d'une icône (Paris, Éditions Textuel, 2017), ouvrage traduit \\ en italien chez Johan \& Levi (Monza, 2019). Il vient de faire paraître l'essai Trop mignon ! Mythologies du cute (Paris, Presses \\ universitaire de France, 2020). E-mail: lavoie.vincent@uqam.ca.
}

\begin{abstract}
Resumo:
A crise migratória de refugiados sírios e iraquianos não escapou da atenção de grandes instituições do fotojornalismo da atualidade. Para além das "obras primas" do fotojornalismo, a iconografia desta crise inclui as "imagens amadoras" realizadas pelos próprios refugiados, conforme os itinerários e as itinerâncias complexas, que desenham uma cartografia movente da migração. São imagens cuja sinceridade e valor demonstrativo inspiraram grandes redes mediáticas (Exodus: nossa jornada à Europa, $B B C, 2016$ ), que as consideraram expressões de uma autenticidade redescoberta. Em seguida, certas propostas artísticas se serviram de tecnologias militares capazes de elaborar mapas térmicos dos fluxos migratórios (Richard Mosse, Incoming, 2017), enquanto questionavam o lugar do espectador diante desta forma de exploração visual. Quais topografias da migração estes três modos de produção visual - jornalístico e canônico, amador e diaspórico, militar e artístico - estabelecem? Quais são as operações políticas a se reconhecer em cada um destes regimes representativos? É ao estudo das tópicas, crenças e perspectivas críticas encontradas no seio dessa triangulação visual do êxodo que este artigo se dedica.
\end{abstract}

\section{Palavras-chave:}

Fotojornalismo; Fotografia Amadora; Êxodo; Vigilância; Incoming.

\begin{abstract}
:
The migratory crisis of Syrian and Iraqi refugees has not escaped the attention of today's major institutions of photojournalism. In addition to the "masterpieces" of photojournalism, the iconography of this crisis includes the "amateur images" made by the refugees themselves, according to the complex itineraries and itinerancies, which draw a moving map of migration. These are images whose sincerity and demonstrative value have inspired great media networks (Exodus: our journey to Europe, BBC, 2016), which have seen them as expressions of rediscovered authenticity. Then, certain artistic proposals made use of military technologies capable of producing thermal maps of migratory flows (Richard Mosse, Incoming, 2017), while questioning the viewer's place in the face of this form of visual exploration.
\end{abstract}

\footnotetext{
${ }^{1} \mathrm{O}$ texto é uma tradução do original Quelle visualité pour l'exode de masse? publicado em francês e inglês na revista Focales - Le recours à l'archive, n. 2, 2018. A autorização para este dossiê foi gentilmente concedida pelo autor, bem como as fotografias autorizadas pelo fotógrafo Richard Mosse. O original pode ser consultado no seguinte URL: https://focales.univ-st-etienne.fr/index.php?id=2173. Acesso em abril de 2020. Tradução de Angie Biondi e revisão de José Benjamim Picado.
}

INTERIN, v. 25, n. 2, jul./dez. 2020. ISSN: 1980-5276. 
Which topographies of migration do these three modes of visual production journalistic and canonical, amateur and diasporic, military and artistic - establish? What are the political operations to be recognized in each of these representative regimes? It is to the study of topics, beliefs and critical perspectives found within this visual triangulation of the exodus that this article is dedicated.

\section{Keywords:}

Photojournalism; Amateur Photography; Exodus; Surveillance; Incoming.

\section{Crise migratória e as virtudes cardeais do fotojornalismo}

World Press Photo, Pulitzer, Nacional Press Photographers Association, Best of Photojournalism, todos os concursos de fotojornalismo do ano de 2016 colocaram, no topo de seu ranking, as imagens da crise migratória. O número de fotografias sobre este tema submetido ao Pictures of the Year International, concurso promovido pelo Reynolds Journalism Institute ${ }^{2}$, foi tão grande que foi preciso criar uma categoria específica - Exxodo - onde nada menos que nove fotógrafos se destacaram. Vários fotojornalistas de renome $^{3}$ perceberam na crise migratória um acontecimento suscetível para pôr em destaque certos valores canônicos da profissão: o tema humanista, o forte teor acontecimental das imagens, a empatia do fotógrafo ${ }^{4}$. Algumas das fotografias laureadas no ano de 2016 foram, neste contexto, particularmente demonstrativas desse ponto. Assim, por exemplo, a fotografia feita por Warren Richardson, vencedor do World Press Photo do mesmo ano, mostra um pai confiando seu filho a mãos salvadoras durante uma migração noturna.

A cena se desenrola na fronteira entre a Sérvia e a Hungria, na noite de 28 de agosto de 2015. O governo húngaro havia acabado de erguer apressadamente um muro de arame farpado, com vistas a impedir que grupos de refugiados sírios, iraquianos e

\footnotetext{
${ }^{2}$ Este instituto é associado à Universidade de Missouri. A Escola de Jornalismo desta Instituição exerceu um papel tutelar no reconhecimento acadêmico do fotojornalismo. Clifton C.Edom atribui inclusive a Frank Luther Mott - que assumiu a direção da Escola em 1942, sede do POYI (agora chamado de FiftyPrint Exhibition Contest) criado em 1944 - a paternidade do termo fotojornalismo. (EDOM, 1976, p. 41)

${ }^{3}$ Lista não exaustiva de fotógrafos que receberam em 2016 algum prêmio por assuntos relativos à crise migratória: Mauricio Lima, Sergey Ponomarev, Tyler Hicks e Daniel Etter/New York Times (Pulitzer; Fabio Bucciarelli/MeMo (POYI); Warren Richardson/freelance (WPPA); Moises Saman e Alex Majoli/Magnum/MSNBC (NPPA; enfi, James Nachtwey (TIME's Best Photojournalism de 2016).

${ }^{4}$ Para um estudo crítico das axiologias do fotojornalismo, ver LAVOIE, 2010.
} 
afegãos entrassem em território europeu. São três horas da manhã, fazia mais de cinco horas que o fotógrafo e os refugiados faziam o jogo de gato e rato com as forças da ordem húngara. A fotografia é tirada sem nenhuma outra iluminação que não a da lua. "Impossível, lembra o fotógrafo, utilizar-se de um flash, pois a polícia estava à sua procura e eu os teria traído" ${ }^{\prime}$. Portanto, esta fotografia tem simultaneamente um êxito técnico - o de fotografar sem iluminação adequada - e a marca de uma posição ética - pois toma a posição de não trair. A imagem borrada, esfumaçada, que poderia, em outras circunstâncias, ter sido por alguém julgada em seu plano formal, encarna na verdade o engajamento moral de um fotógrafo preocupado em preservar a clandestinidade dos migrantes. Hope for a new life é uma imagem fortemente simbólica, cujos recursos retóricos se apoiam em uma série de elementos de contraponto $^{6}$ : a fragilidade da criança e as pontas de arames, a identidade dos protagonistas - quem é, então, o pai? O homem cujo rosto nós vemos? Aquele que se mantém na penumbra? Ou ainda a ambiguidade actancial da cena? - E em qual ação se desenrola mesmo a cena? Por aqui? Por ali? Tal é a ambivalência da imagem, mas sobretudo sua potência, na qual a criança, adormecida na linha de fronteira, sustentada por todas essas mãos benfeitoras, se impõe como uma figura alegórica do exílio. Assim representada, a criança traz à luz a utopia de uma livre mobilidade dos indivíduos; esta miragem dos anos 1990, que os estados não param de dissipar, a partir do fracionamento dos territórios, da construção de muros e do endurecimento de suas regulamentações ${ }^{7}$. A fotografia de Richardson, como sugerida em seu título, se apresenta, não obstante, como o símbolo de uma resistência humanista diante da lógica do Estado.

A meritocracia do fotojornalismo dá a liga a essa sutil mistura de beneficência e singularidade estética. Neste sentido, o ano de 2016 não foi mais excepcional que qualquer outro. A guerra do Vietnã em 1972, o genocídio em Ruanda em 1994, a

\footnotetext{
${ }^{5}$ No original, em inglês: "I was exhausted by the time I took the picture. It was around three o'clock in the morning and you can't use a flash while the police are trying to find these people, because I would just give them away. So I had to use the moonlight alone." (DENHA; KARBOWSKA, 2016)

${ }^{6}$ No original, "contrapuntiques", designando técnicas utilizada em composições musicais nas quais duas ou mais vozes melódicas se sobrepõem levando-se em conta, ao mesmo tempo, o perfil melódico de cada uma delas e a qualidade intervalar e harmônica que é gerada pela sobreposição. $\mathrm{O}$ autor usa o termo adjetivo para estabelecer uma analogia à composição da imagem fotográfica na análise que apresenta, simultaneamente, os dois elementos, o visual e o ético. (N.T.)

7 Ver especialmente DEMOS, 2013.
}

INTERIN, v. 25, n. 2, jul./dez. 2020. ISSN: 1980-5276. 
guerra do Kosovo em 1999 ou o tsunami de 2005 foram também geradores de imagens patéticas e de ícones da compaixão. De fato, as imagens laureadas produzidas durante esses eventos têm em comum o fato de ter dado lugar à expressão de discursos indignados e reprovadores, à manifestações de solidariedade para com as populações devastadas, ou ainda a comentários atestando o poder de influência de tais imagens ${ }^{8}$. A vocação primeira desses concursos consiste em reforçar, por meio da atribuição de valor dessas imagens icônicas, a utilidade social do fotojornalismo.

No entanto, esta safra de 2016 se distingue por um ponto fundamental, pois o êxodo em massa não é um tema como outro qualquer. Devemos a ele o fato de ter trazido à consagração as mais altas aspirações do fotojornalismo de atualidades. Com a guerra civil espanhola notadamente com Robert Capa, nova figura tutelar do fotojornalismo de guerra, que embebe a imprensa ilustrada com inéditos tropos visuais da migração: colunas de refugiados, deslocamentos pelos campos de detenção, infraestrutura sanitária e alimentar, etc. Na esteira da grande depressão, tem-se Dorothea Lange, liderança da fotografia social americana, que publica com Paul Taylor Um Exxodo Americano, obra que documenta o deslocamento de 300 mil americanos para a costa oeste (LANGE e TAYLOR, 1999) ${ }^{9}$. Amplamente difundido pela edição ilustrada, fruto de um trabalho maduro, as imagens de Capa e Lange apenas para citar estes dois nomes - instituíram modelos figurativos, definiram posturas éticas e imputaram certos papeis às imagens de imprensa, das quais aquela, muito criticada por certos historiadores marxistas, de sentimentalismo da prova visual $^{10}$. O êxodo em massa está, portanto, ligado às origens históricas de um fotojornalismo de obediência a uma vocação social e humanitária. Os fotógrafos, como os principais agentes da profissão, não ignoram esta herança, ainda mais que a predominância do tema do êxodo em massa entre os laureados de 2016 proceda, dentre outras coisas, do ressurgimento desse momento fundador. Isto se caracteriza pelas retomadas, mais ou menos literais, dos temas principais do êxodo - migrantes

\footnotetext{
${ }^{8}$ No assunto da influência presumida dos ícones fotojornalísticos sobre o curso dos acontecimentos, vide ROUQUET, 2017. Para uma resenha desta tese de Rouquet, ver GUNTHERT, 2018.

${ }^{9}$ Ver também GOGGANS, 2010.

${ }^{10}$ Em substância, este é o ponto sustentado por John Tagg, ao deplorar que "o estatuto de documento oficial como prova transformou a retórica plana da evidência em um drama sentimentalista da experiência" (TAGG, 1988, p. 12). Ver igualmente BROTHERS, 1997.
}

INTERIN, v. 25, n. 2, jul./dez. 2020. ISSN: 1980-5276. 
escoltados pelas forças da ordem (Sergey Ponomarev), famílias de refugiados instaladas em campos improvisados ou grupos de pessoas reunidas próximos a um posto de fronteira (Petros Giannakouris), aos quais se juntam outros temas mais específicos à crise migratória atual - como o desembarque de migrantes na costa das ilhas de Lesbos ou de Lampedusa (Antonio Masiello), corpos mortos encontrados nas margens (Mauricio Lima), amontoados de coletes salva-vidas abandonados.

É de todo modo através da proximidade física que o fotógrafo mantém com o tema, espécie de assinatura visual do seu compromisso com outrem, que as referências às imagens históricas aparecem com mais evidência. Close-up em rostos angustiados, perspectivas da tomada visual em meio ao tumulto do desembarque ou no turbilhão provocado por uma repressão policial; todos esses atestados fotográficos de uma contiguidade visam assimilar o fotografo à condição de testemunha do evento, status altamente valorizado pela profissão. Uma foto realizada por Tyler Hicks, vencedor do prêmio Pulitzer em 2016, na categoria fotografia instantânea, é um exemplar disso. A fotografia mostra a chegada de um grupo de migrantes da Turquia chegando na costa da ilha de Lesbos. Hicks está entre eles, na água, ou pelo menos, nas pedras do litoral que são atingidos pelas ondas. Ele é também atingido pelas ondas. Uma gota d'água aparece projetada na lente de seu aparelho e, deste modo, confere-lhe um halo desfocado em uma parte da imagem, no canto superior esquerdo. O mesmo ocorre com os desfoques, os enquadramentos imperfeitos e a imprecisão dos focos muito aproximados que conferem uma dimensão fenomenológica à uma fotografia realizada na precipitação ou na clandestinidade ${ }^{11}$; essa gota d'água marca a imagem como um selo de urgência fazendo eco ao tema representado. Os resíduos e acidentes que afetam a composição das imagens fotográficas fazem parte do arsenal de artifícios retóricos, cujo uso em abundância é feito pelos fotógrafos de imprensa. São conhecidos por dar um verniz de autenticidade. Capa o compreendeu perfeitamente: "se desejas ter uma boa foto em plena ação é indispensável não ter uma mira muito rigorosa"12.

\footnotetext{
${ }^{11}$ Ver a análise que Georges Didi-Huberman consagra a quatro famosas tomadas fotográficas feitas em Auschwitz, em agosto de 1944, por membros da resistência polonesa. (DIDI-HUBERMAN, 2003)

${ }^{12}$ Estas falas de Capa foram reportadas pelo jornalista O'Dowd Gallagher, correspondente do London Daily Express, no momento da Guerra Civil Espanhola, durante uma entrevista com Phillip Knightley, principal contraditor de Capa. A prudência nos convida a julgá-los com circunspecção. (KNIGHTLEY, 1976: p. 181)
}

INTERIN, v. 25, n. 2, jul./dez. 2020. ISSN: 1980-5276. 


\section{A autoridade autoral do migrante}

O êxodo em massa aparece nas origens de uma concepção de excelência fotojornalística, indexada à probidade ética do fotógrafo. Dependente da reputação e, ainda mais agora, da sinceridade do autor, tal probidade, garantia de autenticidade das imagens, não é prerrogativa apenas dos fotógrafos profissionais. Os amadores, assim chamados porque são tidos como ignorantes dos "truques" e do sistema de valores que rege a profissão, competem neste nível com os profissionais. Mais do que estes últimos, os amadores, ou mesmo o simples usuário de um celular, para quem a fotografia não passa de um entretenimento, são creditados de uma sinceridade intencional, a qual poucos fotógrafos experientes podem reivindicar.

A crise migratória terá permitido verificar, mais uma vez, esse antigo princípio $^{13}$, atualizando-o de uma maneira inédita. Inédita porque a crise migratória gerou seu próprio sistema de produção iconográfica graças ao uso extensivo de smartphones que garantem a difusão das imagens realizadas pelos próprios migrantes. São eles que dominam muito do repertório visual do êxodo. Essa produção abundante se deve a alguns fatores. O primeiro é de ordem técnica e estatística. Um relatório de 2016 produzido pelo The Open University e France Médias Monde comprova que 98\% da população do Oriente Médio e do norte da África possuem um aparelho celular, a maioria deles, um tipo de smartphone que permite transmitir, pelas redes sociais, as imagens tiradas durante a travessia (GILLESPIE, 2016). Na escala de prioridades, possuir um celular é mais importante que o abastecimento de comida ou mesmo uma acomodação. Isso diz muito sobre a importância adquirida da tecnologia em uma situação de itinerância. O aparelho predileto é um Samsung, já que ele permite a substituição de baterias gastas, algo impossível com um iPhone. A busca por pontos de conexão wi-fi, pontos de venda de cartões SIM, para alterações nos códigos, ou as estações de carregamento de aparelhos também são envolvidos na logística da

\footnotetext{
${ }^{13}$ A autenticidade das imagens feitas por fotógrafos não-profissionais é reconhecida desde a Primeira Guerra Mundial, quando os periódicos ilustrados publicavam chamadas para esses amadores. As comemorações do centenário desse conflito deram lugar à publicação de obras atestando esse fato. (ADAM, 2013)
}

INTERIN, v. 25, n. 2, jul./dez. 2020. ISSN: 1980-5276. 
migração. O Alto Comissariado das Nações Unidas pelos Refugiados reconheceu isso quando distribuiu, a refugiados sírios na Jordânia, 33 mil cartões SIM e 85 mil lanternas solares para recarregar os dispositivos móveis. É importante que os migrantes tenham aquilo que o relatório denomina de "capital de rede", ou seja, um conjunto de recursos tecnológicos necessários à comunicação, ao planejamento de rotas e à proteção das populações.

Um segundo fator que explica a importância quantitativa e estratégica desta iconografia da migração se deve à diversidade dos usos aos quais essa produção visual responde: a manutenção do envio e recepção de imagens como um vínculo permanente com os parentes em situação de migração, ou com aqueles que permaneceram no país de origem, além de documentação do êxodo e constituição de um arquivo visual pessoal, gravação para depoimentos com fins testemunhais ou jurídicos das violências observadas ou sofridas, planejamento e verificação de rotas, ligação com os atravessadores e com os serviços de urgência (pessoal de saúde, ONGs, guarda costeira, etc). A realização de imagens pelos próprios refugiados se inscreve, nesse sentido, no interior de uma estratégia global de sobrevivência.

Fig. 1 - Anônimo, Refugiados registram sua celebração ao alcançar a Praia de Entalou com segurança, na Ilha de Lesbos, Grécia, 2015 (C) Anadolu.

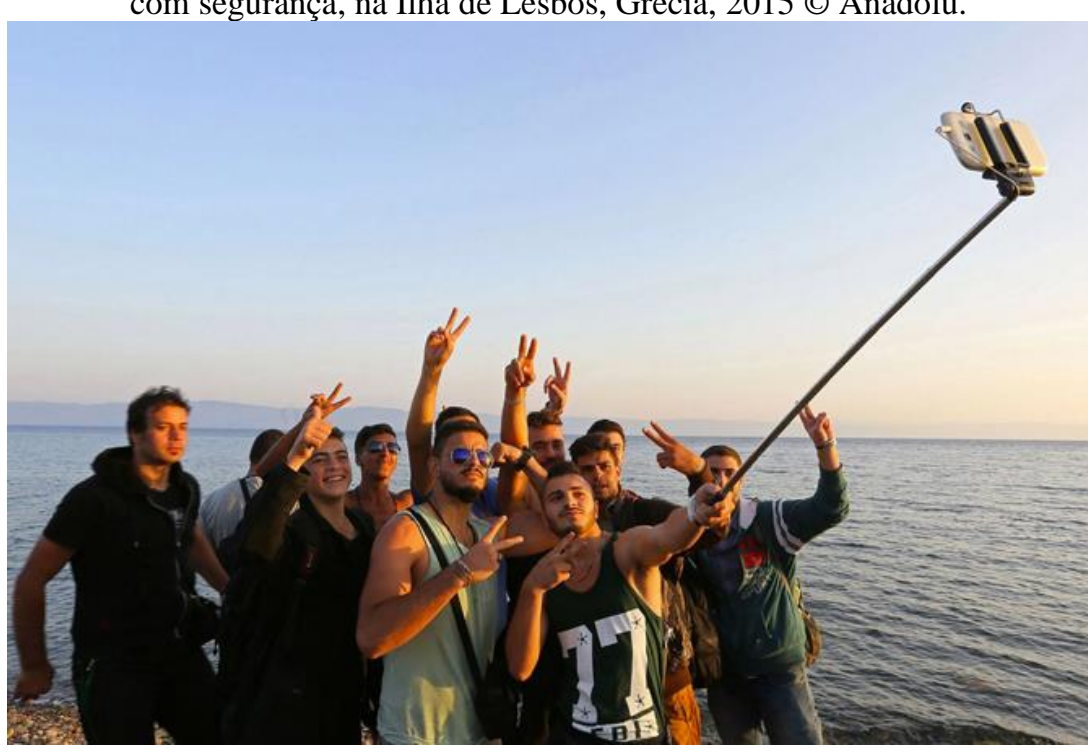

Fonte: Anadolu (2015) (C)

As imagens mais eloquentes são, sem dúvida, as selfies que os refugiados realizam em momentos-chave de sua jornada: o desembarque em terra firme, a chegada em uma área segura ou quando a travessia da fronteira foi realizada. Forma

INTERIN, v. 25, n. 2, jul./dez. 2020. ISSN: 1980-5276. 
comprovada de certificação pessoal, as selfies fornecem provas de que os migrantes ainda estão vivos (fig. 1). A autorrepresentação também se impõe como uma tópica visual muito forte na iconografia da migração. Várias agências de imprensa já divulgaram imagens de homens e mulheres se fotografando como ações próprias às práticas sociais que se utilizam da imagem digital. Ora, muitas destas imagens deram lugar a interpretações prejudiciais aos migrantes. Blogueiros contrários às políticas de acolhimento de refugiados, por exemplo, questionaram a condição indigente destas pessoas relatando o preço dos aparelhos smartphones que elas traziam nas mãos ${ }^{14}$. Era muito pouco conhecida a importância desta tecnologia no processo de migração. Outras pessoas bem intencionadas, no entanto, acreditavam que a difusão destas fotografias que mostram os migrantes fazendo selfies poderia dar a impressão de que a tecnologia atenuava o drama e, portanto, ocultava as raízes políticas do problema. ${ }^{15}$

Esta perspectiva tecno-otimista da crise migratória está marcada no filme Exodus: nossa jornada à Europa, um documentário que a BBC exibiu no outono de 2016. Pondo em destaque o valor deste "capital de rede" e o papel instrumental desempenhado pelas tecnologias móveis no processo de migração, Exodus é um filme realizado a partir de imagens produzidas pelos próprios migrantes, principalmente por aqueles que partiram da Turquia e cruzaram o mar Egeu (fig. 2).

Fig. 2 - Cartaz publicitário do documentário Exodus: our journey to Europe, 2016 (c) BBC2/KeoFilms.

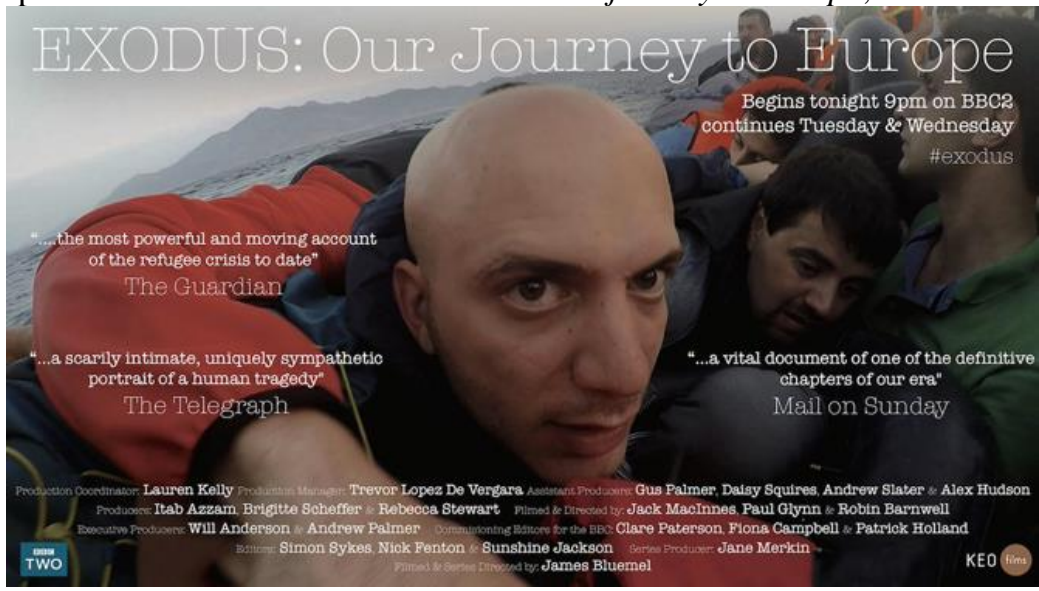

Fonte: BBC2/KeoFilms (2016) @ .

\footnotetext{
${ }^{14} \mathrm{O}$ site cristão Homespun Vine, animado por dois indivíduos que se esforçam em conjugar o amor de Cristo e a paixão pela informação, é a um tal título, até edificante. Vide: «Syrian Refugees Using Expensive Phones To Take Selfies Upon Arriving In Europe », publicado em 5/09/2015. http://homespunvine.com/2015/09/05/. Consultado em 13 jan. 2018.

15 Esta opinião é notadamente a mesma dos relatos que já citamos anteriormente de Marie Gillespie. (GILLESPIE, 2016)
}

INTERIN, v. 25, n. 2, jul./dez. 2020. ISSN: 1980-5276. 
Uma dupla ambição preside a realização deste documentário produzido por James Bluemel e Itab Azzam: de uma parte, ele reconhece que os migrantes têm uma autoridade autoral e uma legitimidade testemunhal, aos lhes confiar o cuidado de autorrepresentarem a própria realidade do êxodo que vivenciam; por outro lado, ele obtém imagens inéditas realizadas do ponto mais próximo possível do acontecimento e realizadas feitas em condições que excluem, a princípio, a presença de fotojornalistas profissionais, ao menos nas cenas realizadas dentro das embarcações improvisadas. A primeira ambição procede de uma ética da representação baseada no reconhecimento de uma legitimidade do ponto de vista e de uma autenticidade dos olhares; a segunda, testemunha o insaciável apetite da mídia por imagens exclusivas, sobretudo, pelos instantâneos das fotos amadoras, uma espécie de fotoverdade como uma arte bruta do fotojornalismo. $\mathrm{O}$ valor de autenticidade atribuído a tais imagens é tão certo, que toda a estética do filme acaba por ser assim afetada.

De fato, a fatura deste documentário é concebida de tal maneira que torna-se difícil distinguir as imagens feitas pelos migrantes daquelas realizadas pela produção. Os migrantes precisam permanecer na clandestinidade, optando por deslocamentos noturnos, usando rotas menos comuns, serviços de atravessadores, etc. Escapar da detenção é uma necessidade. Com efeito, é importante não ser descoberto, e isso compreende também toda sua peregrinação tecnológica, seja nas comunicações criptografadas pelos aplicativos de comunicação como WhatsApp ou Viber, seja usando falsos perfis pelo Facebook ou Twitter, ou ainda utilizando vários cartões SIM pré-pagos. Neste filme, a natureza indistinguível das imagens migrantes decorre de uma metaforização da discrição que seus autores devem observar e respeitar. As imagens estão aí presentes, mas de maneira clandestina, não tanto por serem ilegais, mas sim secretas. Uma clandestinidade estética e não jurídica, já que a identidade dos protagonistas está claramente estabelecida.

Dessa harmonização estética responsável pela indistinção das fontes visuais se desdobram duas observações principais. A primeira se reporta aos regimes de valores aos quais a informação visual está submetida. O exemplo das premiações do fotojornalismo demonstra esse ponto: as imagens de imprensa destacam-se pelas formas de afirmar certo conjunto de cânones estabelecido ao longo do tempo. A excelência fotojornalística é, nesse sentido, muito mais uma questão de deferência. 
Nada disso comparece no documentário da BBC, onde nenhuma axionomia vem estabelecer alguma hierarquia entre as fontes visuais utilizadas. As imagens dos migrantes não são melhores e nem piores que as imagens feitas pela produção. A segunda observação diz respeito justamente a esta indistinção estética e ao valor ético que lhe é associado. Esta indecidibilidade é sobretudo atribuível ao fato da produção ter imitado a estética do vídeo amador como se houvesse, por trás deste ato voluntário de desqualificação profissional, um prestígio qualquer a ser obtido. Assim procedendo, Bluemel e Azzam seguem uma tendência acentuada pelo setor de edição de "reencantar" o domínio da informação visual reproduzindo os atributos de autenticidade das imagens amadoras. ${ }^{16}$

Compreende-se desde então que é a uma ética do testemunho, mais precisamente às formas de atestação pessoal, que se apela aqui. Sobre este ponto, Exodus não se distingue em demasia das imagens laureadas da imprensa-aquelas que, a fim de suscitar a empatia do espectador, destacam as histórias pessoais ou enfatizam as relações subjetivas entre fotógrafos e migrantes. As imagens de Warren Richardson e de Tyler Hicks são exemplares a este respeito. Do mesmo modo, Exodus trata da crise migratória seguindo o percurso de quatro migrantes - Hassan, Isra'a, Ahmad e Sadiq - cujas biografias são reproduzidas nas páginas do site da produção ${ }^{17}$. A personificação do drama do êxodo comparece aí como a condição necessária para o estabelecimento de uma espécie de "situação dialógica" (RICOEUR, 2000), cujo testemunho do migrante atesta perante o outro, a saber, o espectador, a veracidade de sua experiência. $\mathrm{O}$ filme da BBC deixa, assim, pouca liberdade ao espectador, já que ele é impelido ao papel de fiador da palavra de testemunho. Um imperativo ético está na base desta relação que estabelecemos com estas imagens que se utilizam, extensivamente, das retóricas visuais de probidade testemunhal. O mesmo ocorre em imagens de imprensa onde a presença do fotógrafo, à mercê da situação registrada, incorpora, por procuração, o próprio espectador.

\footnotetext{
${ }^{16}$ Esta tendência faz sua aparição no início dos anos 2000. Mais que um simples provedor de imagens amadoras, o telefone celular se impõe agora como plataforma de difusão móvel, ponto nodal de uma nova economia da informação, assim como instrumento de uma redefinição das competências fotojornalísticas, quiçá agente de uma relegitimação da fotografia de imprensa. (PLESSER, 2011; GUNTHER, 2011)

17 <http://www.bbc.co.uk/programmes/articles/kY8dKDD71NV7lpzdctQGf6/the-stories-behind-thejourneys $>$
} 


\section{Incoming (2017) ou a exploração visual reflexiva}

É conhecido o famoso adágio de Robert Capa, palavra de ordem transformada em virtude cardinal do fotojornalismo: "se suas fotos não estão boas o suficiente é porque você não está perto o suficiente". E se tal imperativo da proximidade não for mais suficiente para explicar a complexidade dessas relações? Em 2014, o fotógrafo Richard Mosse e o diretor Trevor Tweeten acompanharam uma operação militar noturna conduzida na cidade síria de Dabiq, a alguns quilômetros da fronteira com a Turquia. Instalados sobre uma colina, os dois artistas puderam observar, através do recurso de uma câmera térmica capaz de restituir a menor fonte de calor a mais de 30 quilômetros de distância, o seguinte conjunto de ações: a rota dos mísseis lançados contra as posições inimigas, os incêndios provocados pelas bombas e ainda o movimento das tropas do Daesh fugindo dos ataques, todas estas ações quase invisíveis à noite, algumas mesmo imperceptíveis, ganharam certa luminescência inédita conferida pelos aparelhos militares.

Fig. 3 - Richard Mosse, Incoming, 2017.

Vista da exposição, Barbican Art Gallery, Londres, 2017.

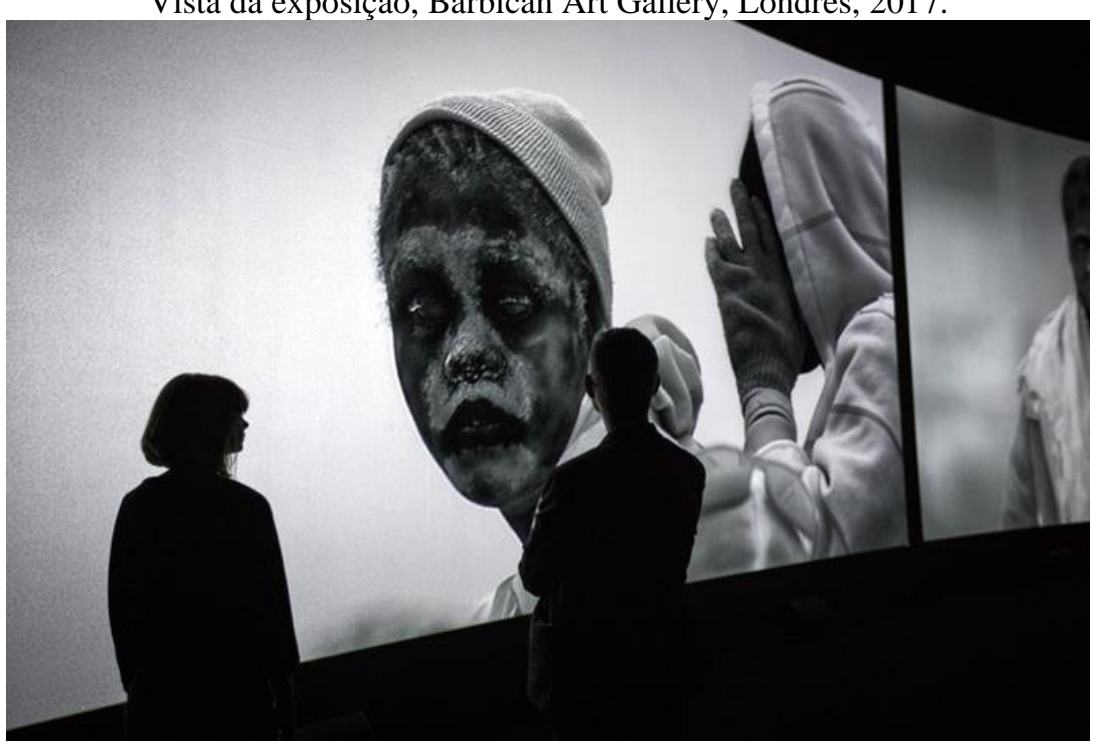

Fonte: () Tristan Fewings/Getty Images for Barbican Art Gallery (2017)

Esta experiência é a base do trabalho Incoming (fig. 3), uma instalação de vídeos em múltiplas telas, com 52 minutos, exibida na primavera de 2017, na galeria 
de arte Barbican, em Londres ${ }^{18}$. Para a realização desta obra, Mosse e Treven usaram a mesma tecnologia militar proibida, que aplicaram a outros temas: movimentos migratórios de populações, resgate em alto mar, grupos de refugiados em situação de detenção ou pessoas fazendo gestos habituais. Nesta obra, os refugiados não são tão visíveis quanto termodetectáveis, assim como os veículos que os transportam, as roupas que vestem ou a água que bebem. Tudo é uma questão de índice térmico: a escuridão do escapamento do veículo, a mancha escura de uma respiração através de um tecido ou ainda a marca das mãos contrastando a brancura de um corpo hipotérmico possivelmente morto (fig. 4 e 5).

Fig. 4 - Richard Mosse, Incoming, 2017.

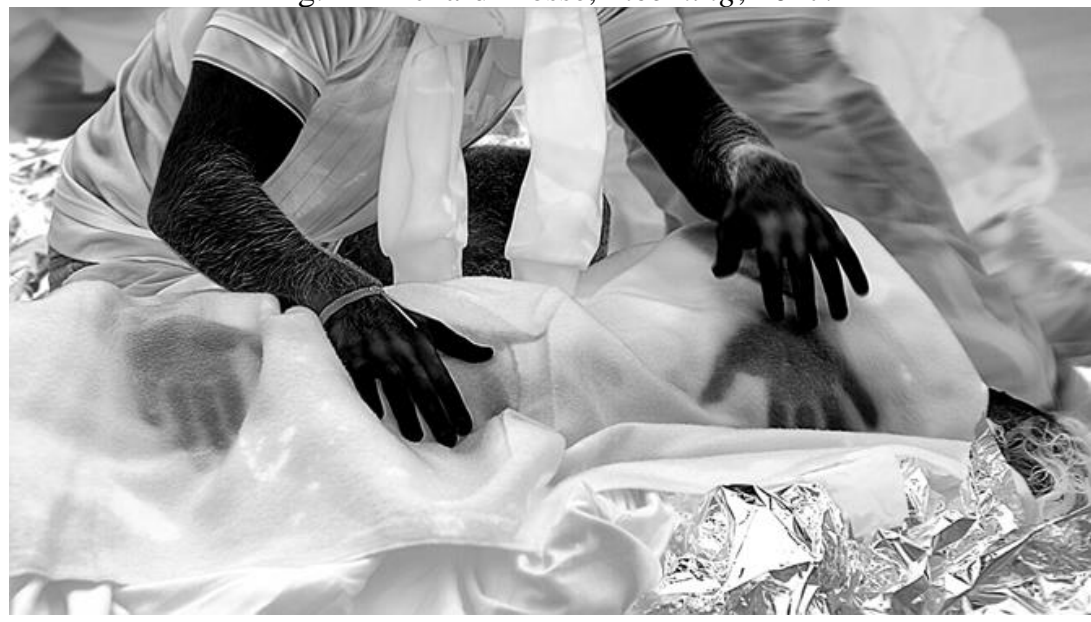

Fonte: Fotograma (C) Richard Mosse, Jack Shainman Gallery, New York and carlier|gebauer, Berlin.

Fig. 5 - Richard Mosse, Incoming, 2017.

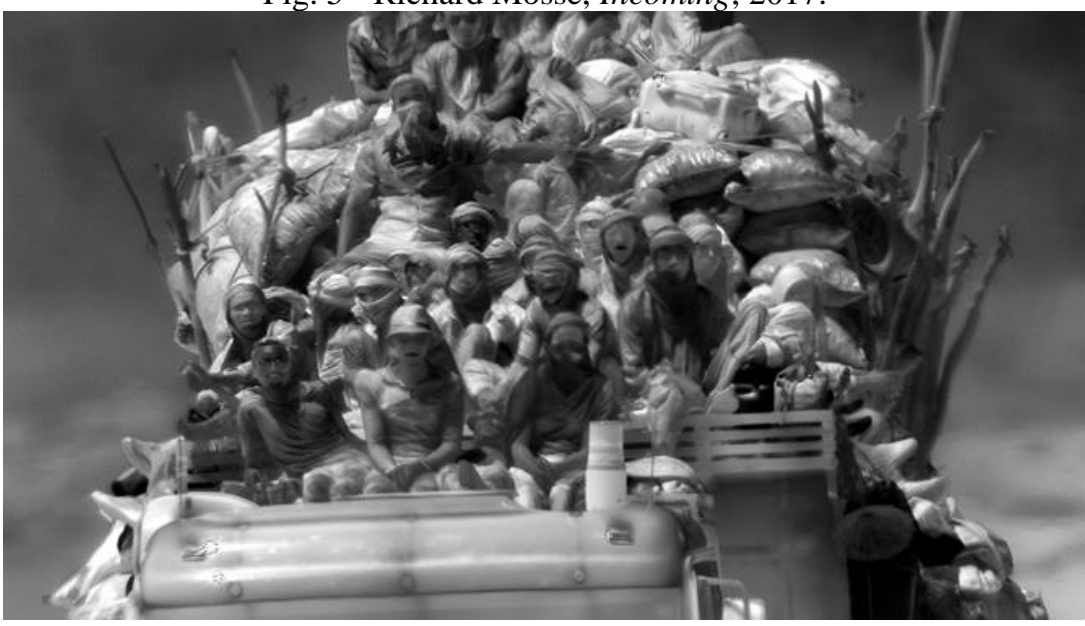

Fonte: Fotograma (c) Richard Mosse, Jack Shainman Gallery, New York and carlier|gebauer, Berlin.

18 As edições Mack, de Londres, publicaram por esta ocasião a obra epônima Incoming. (MOSSE, 2017)

INTERIN, v. 25, n. 2, jul./dez. 2020. ISSN: 1980-5276. 
Essa tecnologia gera imagens cujos rostos são redesenhados de acordo com suas modulações calóricas. É assim que o suor na testa ou o calor de uma respiração remodelam as fisionomias, a ponto de torná-las irreconhecíveis. Algumas pessoas apresentam traços estranhamente inchados, como uma boca entumecida, órbitas sem olhos, uma pele manchada como um padrão de camuflagem. As extremidades e outras partes periféricas do corpo - dedos, nariz, orelhas, cílios, cabelos -, como são pouco ou não são totalmente irrigados pelo sangue, apresentam uma tonalidade clara, ou até mesmo brilhante, contrastando acentuadamente com as demais áreas massivas da anatomia corporal. Assim, desnaturadas, tais pessoas impõem-se a nosso olhar como desprovidas dessa mão estendida que é o rosto.

Incoming elabora uma surpreendente cartografia térmica do êxodo em massa, por meio de uma técnica inicialmente projetada para detectar, perseguir, alvejar. O que pensar desta inversão dos usos, sabendo-se que os empregos militares e civis da termografia estão submetidos a objetivos de segurança? Operacionais à noite e de dia, capazes de farejar qualquer fonte de calor através da fumaça, névoa ou poeira, as câmeras térmicas são notáveis instrumentos de detecção e morte. No momento em que Mosse concebe sua obra, elas continuam a ser utilizadas para controlar e reprimir as populações migrantes, tal como a polícia eslovena, que seguiu os movimentos noturnos da população ou por certas autoridades municipais britânicas, que as utilizam com o objetivo de descobrir pontos de abrigo ilegais (ROBINSON e DUELL, 2013; NEWTON e LINNING, 2015). A indústria civil da vigilância exalta os méritos desta tecnologia para a repressão do crime e da delinquência, enfatizando uma visibilidade expandida promovida por este dispositivo e chamando a atenção da população contra seus usos delituosos - como, por exemplo, a leitura dos resíduos térmicos deixados em um teclado de uma destas máquinas eletrônicas de saque rápido (MOWERY, MEIKELEJOHN e SAVAGE, 2011). O uso do monitoramento termográfico garante uma cobertura permanente de fatos e situações cumprindo, assim, a fantasia de uma visibilidade panóptica do mundo. Uma visibilidade cujo privilégio é, entretanto, essencialmente reservado às autoridades policiais, às empresas e aos Estados. Assim sendo, Mosse recorreu a uma tecnologia que está baseada no princípio de uma visibilidade desigual; alguns - militares e autoridade policiais - veem os outros sem jamais serem vistos, enquanto os demais - inimigos e refugiados - são privados da

INTERIN, v. 25, n. 2, jul./dez. 2020. ISSN: 1980-5276. 
visão daqueles que os olham. Ainda que a distância de muitos quilômetros separe observadores de observados, impedindo assim toda possibilidade de interação entre os protagonistas, Mosse suprime tal hiato, situando-se mais proximamente a seus temas, como faria um fotojornalista. Os vários planos aproximados atestam o efeito desta contiguidade própria às práticas testemunhais da fotografia. A instrumentação atípica empregada pelos artistas e seus assistentes terá feito, aliás, com que tenham sido rapidamente diferenciados dos outros fotógrafos presentes nestes lugares. Objeto de curiosidade por parte dos refugiados, a câmera térmica se tornaria o motivo de um relatório internacional, fato incomum para um dispositivo de exploração visual concebido para escapar da percepção das populações observadas. A presença bem visível sobre os lugares mesmos da tragédia através desta técnica - normalmente dissimulada - marca uma clara ruptura com os usos militares do dispositivo. Acima de tudo, ela manifesta uma intenção de mediação, algo que os fotojornalistas ocultam ou tentam fazer esquecer em nome de um ideal de autenticidade.

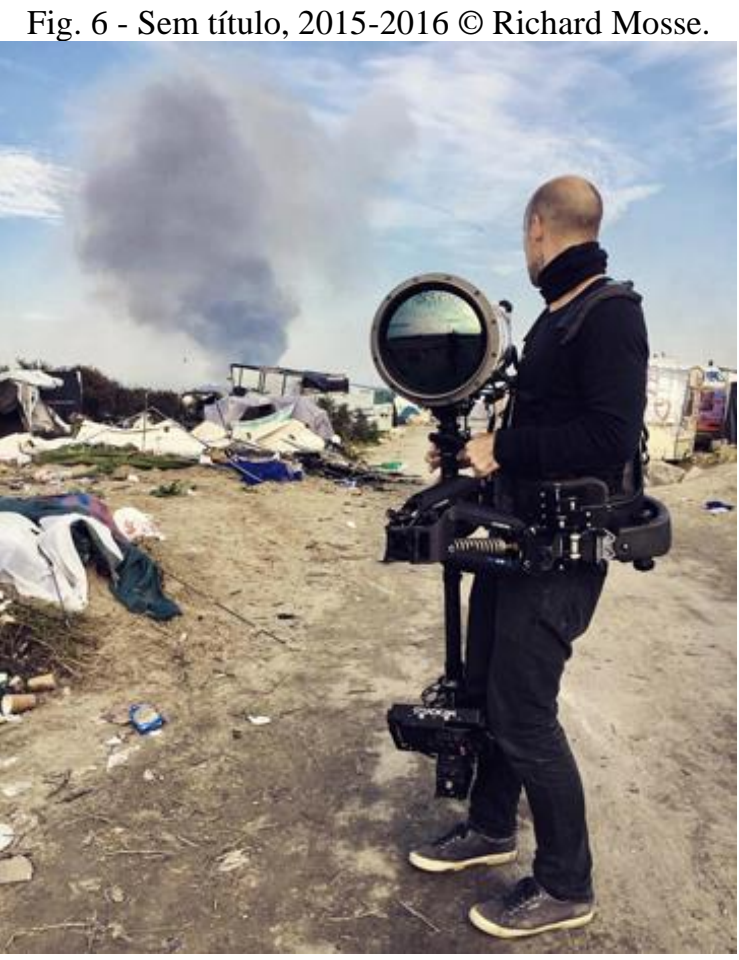

Fonte: Richard Mosse (2016) @

A câmera que Mosse aponta para os refugiados (fig. 6) não tem mais por objetivo caçar essas vidas clandestinas. O calor de seus corpos nunca será aqui a traição de sua presença. Incoming vai além da simples detecção térmica, pois testemunha o

INTERIN, v. 25, n. 2, jul./dez. 2020. ISSN: 1980-5276. 
aspecto estético das imagens que visivelmente excedem toda ambição puramente denotativa e probatória: de aparência leitosa e iridescente, apagam as fisionomias e especificidades étnicas, invertem seus valores, metalizam os corpos e as coisas, alternam as referências em um outro mundo, um mundo de espectros. Essa desrealização do mundo é, inclusive, acentuada por uma trilha sonora electro e nãonarrativa, enquanto o movimento lento das sequências coloca a ação em uma temporalidade distinta da nossa. Como figuras fantasmagóricas, as pessoas parecem caminhar em um espaço liminar, em um tempo indeterminado, em uma clara ruptura com a atualidade pouco apta à permanência para produzir imagens política e afetivamente operatórias. Ao desfilar pelas telas as imagens espectrais, Incoming liberta a representação do refugiado das contingências do presente, pondo assim o espectador em frente ao dilema. Perguntaríamos: qual tipo de relação podemos engajar com essas imagens que apresentam refugiados sem voz, sem real consistência e sem rosto individual? Como conciliar o fascínio que estas imagens podem exercer com a vocação militar da técnica empregada, sabendo que o princípio da apropriação artística não pode constituir um argumento invalidando a violência deste tipo de observação? Se as estéticas da exploração visual permanecem atuantes é porque têm a finalidade de incitar o espectador a adotar uma atitude reflexiva em relação às imagens submetidas que são a sua atenção. Tal é a força de Incomimg: atribuir ao espectador um lugar ambivalente que o conduza a considerar sua função inquiridora, a medir sua distância em relação ao tema e, finalmente, a assumir sua exterioridade diante da crise migratória.

\section{REFERÊNCIAS}

ADAM, Frantz. Ce que j’ai vu de la Grande Guerre. Paris: La Découverte, 2013.

BROTHERS, Caroline. Refugees and the limitations of documentary, In: War and Photography. A Cultural History. London: Routlegde, 1997.

DEMOS, T. J. The migrant image. The art and politics of documentary during global crisis. Durham e Londres: Durham University Press, 2013.

DENHA, Jess; KARBOWSKA, Iwona Karbowska. World Press Photo 2016 winners: Warren Richardson takes top prize with powerful refugees picture. The Independent, 19 fev. 2016. <http://www.independent.co.uk/arts- 
entertainment/photography/world-press-photo-2016-winners-warren-richardsontakes-top-prizewith-powerful-refugees-picture-a6884501.html>. Acesso em $21 \mathrm{fev}$. 2018.

DIDI-HUBERMAN, Georges. Quatre bouts de pellicule arrachés à l'enfer. In: Images Malgré Tout. Paris: Minuit, 2003, p. 11-28.

EDOM, Clifton C. Photojournalism: principles and practices. Dubuque, Wm: C. Brown Company Publishers, 1976.

GILLESPIE, Marie et al. Mapping refugee media journeys: smartphones and social nedia networks. The Open University/France Médias Monde, 13 mai. 2016. <https://www.open.ac.uk/ccig/sites/www.open.ac.uk.ccig/files/Mapping \%20Refugee \%20Media \%20Journeys \%2016 \%20May \%20FIN \%20MG_0.pdf>. Acesso em 03 fev. 2018;

GOGGANS, Jan. California on the breadlines: Dorothea Lange, Paul Taylor, and the making of a New Deal narrative. Los Angeles: University of California Press, 2010 .

GUNTHER, Joel. BBC developing new iPhone app for field reporters. 14 jun. 2011. <http://www.journalism.co.uk/news/bbc-developing-new-iphone-app-for-fieldreporters/s2/a544714/>. Acesso em 21 fev. 2018.

GUNTHERT, André. La matrice du Vietnam et le photojournalisme. L'image sociale: Carnet de Recherches, 09 jan. 2018. 〈https://imagesociale.fr/5339>. Acesso em 01 fev. 2018.

KNIGHTLEY, Phillip. Le correspondant de guerre, de la crimée au Vietnam: héros ou propagandiste?. Paris: Flammarion, 1976.

LANGE, Dorothea e TAYLOR, Paul. An american exodus: a record of human erosion. Édition par Sam Stourdzé. Paris: Sam Stoudzé, 1999.

LAVOIE, Vincent. Photojournalismes: revoir les canons des images de presse. Paris: Hazan, 2010.

MOSSE, Richard. Incoming. Londres: Mack, 2017.

MOWERY, Keaton; MEIKLEJOHN, Sarah; SAVAGE, Stefan. Heat of the moment: characterizing the efficacy of thermal camera-based attacks. In: WOOT'11 Proceedings of the 5th USENIX Conference on offensive technologies, 2011. $\langle$ https://cseweb.ucsd.edu/ kmowery/papers/thermal.pdf $>$. Consultado em $01 \mathrm{fev}$. 2018.

NEWTON, Jennifer; LINNING, Stephanie. Migrants marching through the night: incredible thermal images show vast river of humanity snaking for miles through Slovenia. Daily Mail, 24 out. 2015. <http://www.dailymail. co.uk/news/article- 
3287510/Refugee-children-resorting-survival-sex-pay-people-smugglers-claimsrecord-56-000-migrants-land-Greece-just-six- days.html>. Consultado em 30 mar. 2018.

PLESSER, Andy. New York Times staffer using Apple iPhone 4 for video news Gathering: "A Huge Game Changer" says paper's video chief. 01 fev. 2011. In: <http://www.beet.tv/2011/02/iphone4nytimes.html>. Consultado em 20 fev. 2018.

Wall Street Journal deploying iPhone $\mathbf{4}$ globally for news gathering and live streaming. 10 mai. 2011. <http://www.beet.tv/2011/05/wsjiphone.html>. Consultado em 20 fev. 2018.

RICOEUR, Paul. La Mémoire, l'Histoire, l'Oubli. Paris: Seuil, 2000.

ROBINSON, Martin; DUELL, Mark. Revealed: up to 6.000 beds in sheds" set-up by rogue landlords are found by spy plane's thermal image camera. Daily Mail, 31 jul. 2013. In: <http://www.dailymail.co.uk/news/article-2381451/Slough-spyplane-detects-6-000-illegal-beds-sheds-thermal-imaging.html>. Consultado em 30 mar. 2018.

ROUQUET, Camille. Les Icônes du Vietnam et leur pouvoir: mécanismes de consécration des images photographiques et rhétorique de l'influence des médias depuis la guerre du Vietnam. Tese de Doutorado. Universidade de Paris 7: Paris Diderot, 2017.

TAGG, John. The burden of representation: essays on photographies and Histories. London, Macmillan, 1988, p. 12.

Recebido em: 11/05/2020

Aceito em: 12/06/2020 